\title{
Techniques and Strategies of Critical Thinking Development in the Process of ESL Teaching
}

\author{
H. Tekliuk \\ Vinnytsia State Pedagogical University named after Mykhailo Kotsiubynskyi, Vinnytsia, Ukraine \\ Corresponding author. E-mail: annatekliuk@gmail.com
}

Paper received 31.01.20; Accepted for publication 15.02.20.

https://doi.org/10.31174/SEND-PP2020-221VIII89-10

\begin{abstract}
This paper summarises a study focusing on the techniques and strategies of critical thinking development in the process of ESL teaching. In doing so, it aims to contribute to an important area of research regarding teaching English using new modern approaches. The results of this study successfully reveal that students can acquire critical thinking skills with the help of certain techniques and strategies and use the skills later in life to achieve considerable success in whatever they are doing.
\end{abstract}

Keywords: critical thinking, development, techniques and strategies, thinking skills, ESL teaching.

Introduction. The concept of critical thinking we adhere to reflects a concept embedded not only in a core body of research over the last 30 to 50 years but also derived from roots in ancient Greek. The word "critical" derives etymologically from two Greek roots: "kriticos" (meaning discerning judgment) and "criterion" (meaning standards). Etymologically, then, the word implies the development of "discerning judgment based on standards".

Critical thinking is that mode of thinking - about any subject, content, or problem - in which the thinker improves the quality of his or her thinking by skillfully taking charge of the structures inherent in thinking and imposing intellectual standards upon them.

A well cultivated critical thinker raises vital questions and problems, formulating them clearly and precisely; gathers and assesses relevant information, using abstract ideas to interpret it effectively comes to well-reasoned conclusions and solutions, testing them against relevant criteria and standards; thinks openmindedly within alternative systems of thought, recognizing and assessing, as need be, their assumptions, implications, and practical consequences; and communicates effectively with others in figuring out solutions to complex problems.

Critical thinking is, in short, self-directed, selfdisciplined, self-monitored, and self-corrective thinking. It presupposes assent to rigorous standards of excellence and mindful command of their use. It entails effective communication and problem solving abilities and a commitment to overcome our native egocentrism and sociocentrism [8].

Critical thinking also has an impact on students' interpersonal skills. By thinking critically and seeing things from different angles, students become more open-minded and empathetic, better communicators, more inclined to collaborate with their peers and receive and discuss their ideas. Thinking more about students as individuals, it is possible to say that critical thinking helps them develop their creative side by allowing their thinking process to run more freely, and explore more possibilities. It will make them better decision-makers, and with practice, also help them save time to make those decisions.

A brief overview of publications on the topic.The concept of critical thinking was studied by such authors as Atkinson, D., Campbell, M., Halpern, D. F., Paul, R., Elder, L., Zhao, C. and many others.

The purpose of the article is to overview the publica- tions about techniques and strategies of critical thinking development in the process of ESL teaching.

Results and their discussion. Students can apply critical thinking with the help of lots of different ways, but there are elements in common:

1. Identify the question, that is, what you would like to know;

2. Do research on it. It is important that students use reliable sources of information;

3. Apply the information found in your research to the initial question;

4. Analyze it, and do more research if necessary;

5. Draw conclusions, make decisions, prioritize them;

6. Take action and create steps to make your decisions applicable to the initial question.

It might not always be possible to follow all steps in the language classroom, depending on the activity. That means we should teach and encourage critical thinking. It can be as simple as asking "Why?" when someone makes a statement in class, or "How do you know?", or "Where did you see that?" The goal is to have them start thinking about it from different angles, in new ways.

If we are trying to foster quality thinking, we do not want students simply to assert things; we want them to try to reason things out on the basis of evidence. Often, teachers are unclear about this basic difference. Many teachers are apt to take student writing or speech which is fluent and amusing as good thinking. They are often unclear about the constituents of good reasoning. Hence, even though a student may just be asserting things, not reasoning things out at all, if they do so with confidence, teachers tend to take this to be equivalent to good reasoning [8].

In case you feel your students do not have the language necessary to express themselves in English, you may want to have them use their thinking skills by exploring the space they are in. Total Physical Response (TPR) activities are also helpful, for they associate language and movement, and students start "producing language" by responding with their bodies.

For activities that are about the language, you can have students categorize words (good for vocabulary learning), make comparisons, memorize or sequence (facts in a story, names), think of cause and effect, and so on. Not only do these activities activate their thinking skills, but they are also very practical - you can fit them in any moment of the 
lesson [6].

If you have more time, you can go through all the steps above as the process for something bigger - a project, for instance. Projects also promote creativity and collaboration in class, for students will have to put their minds together and negotiate meaning, solve problems, and create something that will be the end product of the project. Another possibility is to flip the class - have students do research before class, and bring their findings to be applied to a topic proposed and have an informed discussion about it [1].

These suggestions may be used with students at different ages, but we also must remember our role as teachers, and the things we should do to reach the end goal, which is to make them think critically. In that regard, there are some things we should consider.

The first one is to start early: it's important to choose the activity for the children's age and level. Secondly, we should avoid answering students' questions right away: teachers want to help students by giving them the replies so they can move on with the task quicker, but if the main goal is to make them think critically, you may want to give them time to find the answers on their own.

Alternatively, have them work in pairs or groups and try to find the answers together. That is not just an opportunity to foster collaboration, but you may be surprised at how creative your students get [10].

Thirdly, avoid asking low-level questions, that is when we address details, facts or figures, aim to use only shortterm memory and base on memorization, but not understanding. It is necessary to ask and encourage high-order open-ended questions. It means to ask how or why something happens or happened, ask questions which require application of details to larger context and critical thinking, go beyond facts to constructing a rationale. To help students form higher-level questions, teachers can provide students with generic question stems as prompts. For example, a question stem such as "How does...affect...?" calls for the skill of analysis of relationship among ideas (cause-and-effect); the question "What would happen if..." requires making predictions; "Do you agree or disagree with this statement: ...? Support your answer." It is expected that as they regularly and frequently pose and answer questions of others and their own, students develop their skills and habit of questioning and begin to become critical thinkers. Whenever it is possible, allow learners to ask you and their classmates questions.

There are some strategies for effective questioning techniques. The first one is to ask questions that invite more than one answer. Another one is to provide wait time after asking a question to give less confident students time to think. Teachers also should ask follow-up questions, such as, "What can you add?" or "What is your opinion?" and provide feedback that neither confirms nor denies students' responses to ensure the discussion remains open. Examples are: "Interesting." or "I hadn't thought of that." We might also request a summary, e.g. "Who can make the point in different words?", survey the other students: "Who agrees with Max? Who disagrees? Why?", encourage students to direct questions to other students or play devil's advocate: "How would you feel if...?"

The detailed list of probing questions presented by Paul and Elder can be applied to English language classrooms: questions for clarification (e.g., "Could you please explain further?"); questions about different viewpoints or perspectives (e.g., "What would someone who disagrees say?"); and questions to challenge or probe students' assumptions, reasons, evidence, implications, and purposes [8].

Moreover, language teachers should avoid answering their own questions after a short silence time, a common harmful teaching habit that shifts the work of thinking and learning away from learners.

To teach critical thinking teachers must create a culture of inquiry by supporting students' thinking process, model critical thinking skills, actively question students' thinking and guide reflecting on the thinking process, etc. [3]

Teachers should also encourage understanding and respect: one of the consequences of exercising critical thinking is the development of intellectual empathy, which is the capacity to put oneself in someone else's place and understand their thoughts and feelings.

It is not just about science and facts: critical thinking will not only make students intellectual empaths, but it will also help them become aware of their own knowledge and the need to address different ideas constantly. We could apply their skills to discuss issues from other subjects, such as Math, Literature, History, Sociology, or moral issues, etc. [7]

One can define three sets of research-supported teaching strategies which are useful in promoting CT and applicable to EFL classrooms; that is, explicit instruction, teacher questioning, as well as active and cooperative learning strategies [2].

Recent tendencies in English as a foreign language (EFL) have highlighted the significance and necessity of developing critical thinking. In English language learning, students need CT skills to read and analyze, to write essays, to express their ideas with adequate supporting evidence, proficient learners must be able to use CT.

Despite wide acknowledgement of the significance of fostering students to be critical thinkers, there has been debate concerning the teachability of CT in the EFL context. Atkinson especially expresses doubt about the feasibility of teaching CT to EFL learners; in his view, CT is a "social practice" [1, p. 72] inherent in Western culture and can only be acquired through an unconscious process of socialization during childhood.

To help students develop in CT, researchers have suggested adopting active and cooperative learning which focuses on student participation, cooperation, and interaction. Some of the proposed strategies include role play/simulation, group research projects, a method which involves investigation or surveys about a certain topic and the reporting of the findings in various ways (presentations, newspapers, plays, skits, debates) [2]. Group discussion, debate, and peer-questioning are recommended as three basic effective strategies that can be applied in EFL classrooms [10].

Effective group discussions depend on the provision of group goals to learn something, individual accountability, and student engagement. In order to promote CT and student involvement in EFL classrooms, it is crucial to instruct students the ground rules and skills for group discussion, such as listening attentively, responding appropriately, inviting others to respond, asking clarifying questions, etc. Teachers need to choose thought-provoking topics that are 
relevant to students' life experience and can evoke interests; cultural differences, controversial issues, current events, and moral dilemma may be of good service [9].

Debate, a formal discussion method, is another ideal teaching tool for developing CT. As a form of active learning, debate induces students to research a topic profoundly, ask questions, identify contradictions and errors, and formulate evidence-based arguments [10].

Using debate activities in ESL/EFL courses is recommended; choosing controversial issues for students to debate can not only increase student participation and language use, but also facilitate CT development [4].

As a typical debate presents only two views ("for" or "against"), other forms of debate can be used as well. For example, four-corner debate where students may choose one of the four positions ("strong agree", "agree", "disagree", or "strong disagree") on a topic to argue; and roleplay debate, a format in which students are assigned to take on different roles and argue on behalf of several perspectives of a problem [5].

Without focusing on any specific teaching strategies, some researchers seek to explore the common features of teaching strategies or classroom practices that are found to be effective in promoting CT. There are some characteristics of effective CT instruction, which include introducing CT skills related to content, providing lots of opportunities to practise the skills, inclusion of students in classroom decision-making, and creating an emotionally safe learning environment. As most CT instruction gives more priority to the "cognitive skill" perspective of CT, it is worth noting that the above studies also accentuate the importance of establishing an encouraging learning environment where CT is encouraged, expected, and valued. The affective or dispositional dimension of CT is hence highlighted [7]. Therefore, it is vital that teachers create a classroom environment where students are encouraged to probe assumptions, ask important questions, and evaluate reasons through teacher-student and student-student interactions. To construct a classroom culture for CT, teachers themselves can act as role-models or create conditions in which different perspectives are expressed and confronted with each other. Teachers' feedback and their attitude toward the critical features of students' work impact students' development in CT attitudes and CT skills [10].

There are also other various ideas and stages which we must take into consideration. Firstly, it is learning how to apply the critical thinking approach to ourselves, teachers. Teachers should check their own knowledge of a topic before introducing it to their students. Secondly, it is teaching students to use critical thinking while learning. If you manage to give them the basics, they may use those acquired skills later in life and achieve considerable success in whatever they are doing. Thirdly, as an absolute majority of school children in the world $(85 \%)$ list communication with their peers as the main reason for attending school, we should use an individual student's interests and aspirations. It is also important to explain that being critical does not mean criticise. Many students would refuse to speak up and express their ideas for fear of ridicule. If a teacher has a habit of scolding or making fun of a child who makes mistakes, then any attempt at developing critical thinking will fail. The feeling of resentment may only grow; it is never a good companion to successful learning.

Furthermore, if we manage to teach our students how to think, how to approach the new data creatively and how to apply their knowledge in the future, we may produce some very productive members of any society. The ability to think, evaluate and re-think if/when needed is a great skill which we may foster and nurture even in very young children [10].

Conclusion. To sum up, common features of effective CT instruction generally involve direct instruction, frequent practice, intense student interaction, and a supportive CT classroom climate. In designing CT activities in the classroom, teachers need flexibility and creativity; they may use and combine various strategies in a new way or develop alternative methods appropriate to their own classes. Effective CT instruction in EFL classrooms depends on teachers' deliberate and persistent efforts. Such strategies as group discussion, debate, and reciprocal questioning, etc. can be used as effective ways to enhance students' CT in EFL classes. Teachers should provide appropriate guidance and enough chances for students to interact with each other and share different ideas.

\section{REFERENCES}

1. Atkinson, D. (1997). A critical approach to critical thinking in TESOL. TESOL Quarterly, 31(1), 71-94. http://dx.doi.org/10.2307/3587975

2. Campbell, M. (2015). Collaborating on critical thinking: The team critique. Journal of Curriculum and Teaching, 4(2), 86-95. http://dx.doi.org/10.5430/jct.v4n2p86

3. Halpern, D. F. (2007). The nature and nurture of critical thinking. In R. J. Sternberg, H. L. Roediger, \& D. F. Halpern (Eds.), Critical thinking in psychology (pp. 1-14). Cambridge: Cambridge University Press.

4. Halvorsen, A. (2005). Incorporating critical thinking skills development into ESL/EFL courses. The Internet TESL Journal, 11(3). Retrieved from http://iteslj.org/Techniques/Halvorsen-CriticalThinking.html

5. Kennedy, R. (2007). In-class debates: Fertile ground for active learning and the cultivation of critical thinking and oral communication skills. International Journal of Teaching and Learning in Higher Education, 19(2), 183-190.

6. Liu, W., \& Guo, H. Y. (2006). An experimental study on the teaching of critical reading. Foreign Language World, (3), 1423.

7. Mathews, S. R., \& Lowe, K. (2011). Classroom environments that foster a disposition for critical thinking. Learning Environments Research, 14(1), 59-73. http://dx.doi.org/10.1007/s10984-011-9082-2

8. Paul, R., \& Elder, L. (2008). The miniature guide to critical thinking: Concepts and tools (5th ed.). Tomales, CA: Foundation for Critical Thinking Press.

9. Shirkhani, S., \& Fahim, M. (2011). Enhancing critical thinking in foreign language learners. Procedia-Social and Behavioral Sciences, $29, \quad 111-115$. http://dx.doi.org/10.1016/j.sbspro.2011.11.214

10. Zhao, C. Instructional Strategies for Developing Critical Thinking in EFL Classrooms // English Language Teaching Vol. 9, No. 10; 2016. elt.ccsenet.org 